Jurnal IImiah : Biologi Eksperimen dan Keanekaragaman Hayati

Vol. 2 No. 1 Mei 2014 : hal. 41-45

ISSN : 2338-4344

\title{
KEANEKARAGAMAN KUPU-KUPU NYMPHALIDAE DI PULAU PUHAWANG BESAR, TELUK LAMPUNG
}

\section{DIVERSITY OF NYMPHALID BUTTERFLY IN PUHAWANG BESAR ISLAND, TELUK LAMPUNG}

\author{
Kurniawati Achmad $^{1}$, Herawati Soekardi ${ }^{1}$, Nismah Nukmal ${ }^{1}$ dan Martinus ${ }^{2}$ \\ 1Jurusan Biologi Fakultas MIPA Universitas Lampung \\ 2Jurusan Teknik Mesin Fakultas Teknik Universitas Lampung \\ *e-mail : koernhea.ach@gmail.com \\ Jurusan Biologi Fakultas MIPA Universitas Lampung \\ Jl. Soemantri Brojonegoro No.1, Bandar Lampung, Lampung, Indonesia, 35145
}

\begin{abstract}
Abstrak
Tujuan dari penelitian ini adalah untuk mempelajari keanekaragaman dan kemelimpahan spesies kupu-kupu Nymphalidae di Pulau Puhawang Besar, Lampung. Penelitian ini dilaksanakan di Pulau Puhawang Besar pada bulan Agustus-September 2013. Metode yang digunakan adalah metode Pollard dengan menelusuri rute jalan setapak yang ada sepanjang 8,6 km. Hasil penelitian menunjukkan bahwa jumlah individu kupu-kupu Nymphaidae yang ditemukan di Pulau Puhawang Besar sebanyak 59 individu, terdiri dari 11 spesies dan termasuk dalam 6 Subfamili, yaitu Biblidinae, Danainae, Heliconiinae, Limenitidinae, Nymphalinae, dan Satyrinae. Indeks keanekaragaman kupukupu Nymphalidae di Pulau Puhawang Besar termasuk dalam kategori sedang $(1,90)$. Kemelimpahan kupu-kupu relative tertinggi ditunjukkan oleh Ypthima baldus sebesar 37,29\%, diikuti Danaus melanipus sebesar $20,34 \%$, dan Orsotriaena medus sebesar $11,86 \%$ sedangkan kupu-kupu yang memiliki kemelimpahan relatif terendah yaitu Cupha erymanthis dan Euthalia monina (1.69\%).
\end{abstract}

Kata Kunci : Nymphalidae, Pulau Puhawang Besar, keanekaragaman, kemelimpahan

\begin{abstract}
The objective of the research was to study the diversity and abundance of Nymphalid butterfly in the Puhawang Besar Island, Lampung. The research have been conducted from August until September 2013. The method used is the Pollard walk method along the trail of $8,6 \mathrm{~km}$. The result showed that the number of Nymphalid found in the Puhawang Besar Island were 59 individuals, belong to 11 spesies and 6 Subfamily, namely Biblidinae, Danainae, Heliconiinae, Limenitidinae, Nymphalinae, and Satyrinae. The diversity index of Nymphalid in the Puhawang Besar Island can be categorized as medium (1,90). Across the island and the study time elapse, Ypthima baldus showed the highest species relative abundance $(37,29 \%)$, followed by Danaus melanipus $(20,34 \%)$, and Orsotriaena medus $(11,86 \%)$. Meanwhile Cupha erymanthis and Euthalia monina occurred in the lowest relative abundance $(1,69 \%)$.
\end{abstract}

Keyword : Nymphalidae, Puhawang Besar Island, diversity, abundance

\section{PENDAHULUAN}

Indonesia merupakan negara tropis yang memiliki keanekaragaman hayati yang tinggi baik flora dan fauna dan tersebar luas baik di daratan dan di lautan. Salah satu fauna yang jumlahnya terbanyak dan tersebar luas adalah serangga (Tsukada dan Nishiyama, 1982) dan serangga yang sering dijumpai adalah kupukupu (Lepidoptera). Jumlah Leptidoptera yang telah dideskripsi di dunia sekitar 200.000 spesies (Gillot, 2005). Menurut Soekardi (2007), jumlah spesies kupu-kupu yang terdapat di Indonesia belum ada data yang pasti. Begitu juga di Sumatera, walaupun data keanekaragaman kupu-kupu di Sumatera belum lengkap diperkirakan terdapat tidak kurang dari 1.000 spesies. Salah satu provinsi di Sumatera yang memiliki keanekaragaman kupu-kupu adalah Lampung. Keanekaragaman kupu-kupu di Lampung antara lain tersebar di Taman Nasional Way Kambas terdapat 77 spesies dan Taman Nasional Bukit Barisan Selatan 185 spesies.

Kupu-kupu anggota famili Nymphalidae memiliki ukuran tubuh yang beranekaragam serta memiliki banyak variasi pola warna dan bentuk sayap. Pada umumnya, sayap berwarna coklat, 
orange, kuning, dan hitam (Peggi dan Amir, 2006). Menurut Mastrigt dan Rosariyanto (2005) panjang sayap depan berkisar 1,5-7,0 $\mathrm{cm}$. Ukuran tubuh kupu-kupu ini beranekaragam mulai dari yang kecil sampai besar.

Ciri khas famili Nymphalidae yang membedakannya dengan famili lainnya adalah dalam hal pasangan tungkai depan yang tereduksi dan mengecil berbentuk seperti sikat dan terlipat pada tubuh pada waktu hinggap sehingga famili Nym-phalidae sering disebut dengan kupu-kupu ber-kaki sikat atau the brush footed (Mastrigt dan Rosariyanto, 2005 ; Peggi dan Amir, 2006).

Penelitian keanekaragaman kupu-kupu di dua pulau kecil Teluk Lampung yang pernah dilakukan yaitu di Pulau Tegal dan Tanjung Putus (Larasati, 2003). Selain itu terdapat pula pulaupulau kecil yang terdapat di perairan Teluk Lampung, diantaranya adalah Pulau Puhawang Besar dan Pulau Puhawang Kecil. Akan tetapi ada pulau-pulau kecil di perairan Teluk Lampung belum diteliti keanekaragaman dan kemelimpahan kupu-kupunya.

\section{BAHAN dan METODE}

Penelitian ini telah dilaksanakan di Pulau Puhawang Besar, Teluk Lampung dari bulan Agustus-September 2013. Dalam penelitian ini dilakukan survei keanekaragaman dan kemelimpahan kupu-kupu Nymphalidae dengan menggunakan metode jelajah dengan menelusuri rute jalan setapak. Dalam kegiatan ini dilakukan pencatatan spesies dan jumlah masing-masing individu spesies kupu-kupu Nymphalidae yang terlihat di jalur jelajah atau pengamatan yaitu sejauh $5 \mathrm{~m}$ di kiri dan kanan jalur dalam lembar kerja.

Dalam kegiatan survei ini kupu-kupu yang belum dikenali ditangkap dengan menggunakan jaring kupu-kupu. Kupu-kupu yang telah ditangkap ditekan pada bagian thoraks sampai kupukupu lemas kemudian dimasukkan dalam amplop spesimen.

Spesimen dibawa ke laboratorium dan disuntik alkohol 70\% kemudian kupu-kupu direntangkan di gabus styrofoam. Selanjutnya spesimen kupu-kupu diinkubasi pada suhu $40^{\circ} \mathrm{C}$ selama seminggu. Kemudian spesimen kupu-kupu diidentifikasi menggunakan acuan (Novita, 2006 ; Soekardi, 2007; Handawa, 2007; Noprihatini, 2007; Wibowo, 2009) dan masing-masing spesies kupu-kupu Nymphalidae discan untuk agar diperoleh gambar.

\section{HASIL dan PEMBAHASAN}

\section{Keanekaragaman Kupu-kupu Nymphalidae di Pulau Puhawang Besar}

Selama rentang waktu penelitian di sepanjang jalur pengamatan di Pulau Puhawang Besar, Kupu-kupu Nymphalidae yang teramati sebanyak 59 individu, tergolong dari 11 spesies dan 6 subfamili ( Tabel 1 ).

Tabel 1. Pengelompokan spesies Nymphalidae berdasarkan subfamili

\begin{tabular}{ll}
\hline \multicolumn{1}{c}{ Subfamili } & \multicolumn{1}{c}{ Spesies } \\
\hline Biblidinae & Ariadne ariadne \\
Danainae & Danaus melanipus \\
Heliconiinae & Cupha erymanthis \\
Limenitidinae & Neptis hylas \\
Nymphalinae & Junonia almana \\
& Junonia atlites \\
& Euthalia monina \\
& Hypolimnas bolina \\
Satyrinae & Elymnias hypermnestra \\
& Orsotriaena medus \\
& Ypthima baldus \\
\hline
\end{tabular}

Jumlah spesies dan kemelimpahan kupu-kupu Nymphalidae yang ditemukan dari hasil penelitian lebih sedikit dibandingkan jumlah spesies kupu-kupu Nymphalidae yang ditemukan pada tiga daratan utama Provinsi Lampung. Di Pulau Puhawang Besar keanekaragaman kupu-kupu Nymphalidae lebih sedikit dibandingkan tempat yang lain di Provinsi Lampung. Di Taman Nasional Way Kambas ditemukan 32 spesies kupukupu Nymphalidae (Novita, 2006). Menurut Noprihatini (2007) tercatat 34 spesies kupukupu Nymphalidae yang ditemukan di daerah Canguk Taman Nasional Bukit Barisan Selatan. Keanekaragaman kupu-kupu Nymphalidae di kawasan Waduk Batutegi, tercatat sebanyak 34 spesies (Handawa, 2007). Keanekaragaman spesies kupu-kupu Nymphalidae di suatu pulau tergantung pada luas pulau tersebut. Berdasarkan Teori Biogeografi pulau-pulau yang besar dan dekat dengan daratan utama memiliki jumlah spesies kupu-kupu yang lebih banyak dibandingkan pulau-pulau yang kecil dan jauh dari daratan utama (Sumarto dan Siahaan, 2012). Pulau Puhawang besar memiliki luas 694 ha. Pulau ini lebih kecil dari tiga daratan utama (Taman Nasional Way Kambas, Canguk Taman Nasional Bukit Barisan Selatan, dan kawasan Waduk Batutegi) Provinsi Lampung.

Perbedaaan jumlah spesies kupu-kupu Nymphalidae yang ditemukan pada beberapa tempat juga diduga karena adanya perbedaan keanekaragaman tumbuhan sebagai tumbuhan inang dan tumbuhan penghasil nektar. Keanekaragaman tumbuhan inang pada suatu habitat berpengaruh terhadap keberadaan kupu-kupu 
(Widhiono, 2004). Tumbuhan inang yang terdapat di Pulau Puhawang Besar diantaranya Asystasia intrusa, Imperata cylindrica (ilalang), Cocos nucifera (kelapa), dan Flacourtia rukam (rukam). Sedangkan tumbuhan penghasil nektar Asystasia intrusa, Lantana camara (puyengan), Stachytarpheta indica (jarong), Ageratum conyzoides (bandotan), Hibiscus rosa-sinensis (kembang sepatu), Bougenvillea spectabilis (bugenvil), dan Ixora paludosa (bunga soka). Tumbuhan penghasil nektar tersebut sebagian besar merupakan tanaman pakan imago Nymphalidae. Selain itu, faktor yang mempengaruhi perbedaan jumlah spesies kupu-kupu Nymphalidae yang ditemukan adalah faktor fisik seperti suhu. Suhu pada saat dilakukan penelitian berkisar antara $32-37^{\circ} \mathrm{C}$. Perbedaan keragaman kupu-kupu sangat berkaitan dengan faktor lingkungan, diantaranya suhu, curah hujan, dan cahaya (Boonvanno et al., 2000).

\section{Kemelimpahan Relatif Kupu-kupu Nympha- lidae di Pulau Puhawang Besar}

Kupu-kupu Nymphalidae yang mendominasi Pulau Puhawang Besar (Tabel 2) adalah Ypthima baldus $(37,29 \%)$. Kupu-kupu ini dapat ditemukan di sepanjang jalur jelajah. Menurut Soekardi dkk. (2001) faktor yang mempengaruhi kemelimpahan kupu-kupu adalah keanekaragaman tumbuhan inang dan tumbuhan penghasil nektar sehingga ketersediaan tumbuhan inang dan tumbuhan penghasil nektar berkaitan dengan tingginya nilai kemelimpahan relatif kupukupu Ypthima baldus. Pada setiap jalur jelajah terdapat Imperata cylindrica yang merupakan tumbuhan inang bagi Ypthima baldus. Hal ini yang diduga menjadi penyebab berlimpahnya Ypthima baldus di lokasi penelitian dibandingkan spesies yang lainnya. Menurut Peggi dan Amir (2006) tumbuhan inang Ypthima baldus adalah famili Poaceae dan spesies ini banyak ditemukan di padang rumput.

Spesies kupu-kupu Nymphalidae Danaus melanipus (Tabel 2 dan Gambar 1) juga banyak ditemukan di Pulau Puhawang Besar dan memiliki kemelimpahan relatif tertinggi kedua $(20,34 \%)$. Kupu-kupu ini banyak ditemukan dalam keadaan terbang secara berpasangan. Selain itu, Orsotriaena medus juga merupakan kupu-kupu yang banyak ditemukan dan memiliki kemelimpahan relatif ketiga $(11,86 \%)$.

Cupha erymanthis dan Euthalia monina merupakan dua spesies yang populasinya sangat kecil, hanya ditemukan satu individu dan masing-masing memiliki kemelimpahan relatif terendah (1,69 \%) (Tabel 2 dan Gambar 1). Sangat rendahnya kemelimpahan relatif ini diduga karena kurangnya tumbuhan sebagai inang dan penghasil nektar bagi kupu-kupu tersebut. Tumbuhan inang Cupha erymanthis adalah Fla- courtia rukam (rukam). Tumbuhan ini ditemukan dalam jumlah yang sedikit dan tidak ditemukan pada setiap tempat di sepanjang jalur jelajah. Selain itu juga, sedikitnya jumlah kedua spesies tersebut pada saat penelitian kemungkinan disebabkan karena kedua spesies tersebut masih berada pada fase yang tidak aktif misalnya masih dalam fase telur, larva, atau pupa.

Tabel 2. Kemelimpahan relatif kupu-kupu Nymphalidae di Pulau Puhawang Besar

\begin{tabular}{clcc}
\hline No & \multicolumn{1}{c}{ Spesies } & Jumlah & KR (\%) \\
\hline 1 & Ariadne ariadne & 2 & 3,39 \\
2 & Cupha erymanthis & 1 & 1,69 \\
3 & Danaus melanipus & 12 & 20,34 \\
4 & Elymnias hypermnestra & 2 & 3,39 \\
5 & Euthalia monina & 1 & 1,69 \\
6 & Hypolimnas bolina & 5 & 8,47 \\
7 & Junonia almana & 2 & 3,39 \\
8 & Junonia atlites & 2 & 3,39 \\
9 & Neptis hylas & 3 & 5,08 \\
10 & Orsotriaena medus & 7 & 11,86 \\
11 & Ypthima baldus & 22 & 37,29 \\
\hline & Jumlah & 59 & 100
\end{tabular}

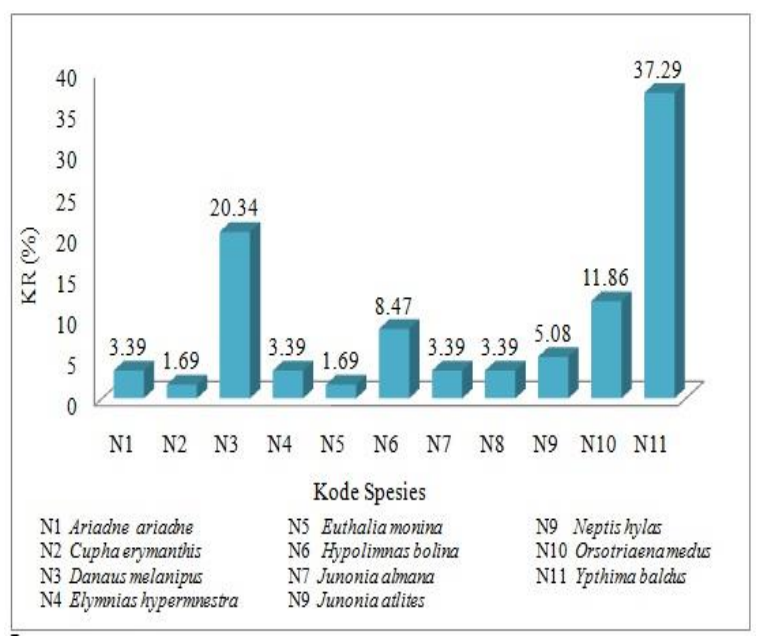

Gambar 1. Kemelimpahan relatif kupu-kupu Nymphalidae di Pulau Puhawang Besar

\section{Indeks Keanekaragaman Kupu-kupu Nym-} phalidae di Pulau Puhawang Besar

Nilai indeks keanekaragaman kupu-kupu Nymphalidae di Pulau Puhawang sebesar 1,90. Nilai tersebut termasuk dalam kategori sedang (Magguran, 1983). Indeks keanekaragaman dalam kategori sedang diduga masih tersedianya tumbuhan inang dan tumbuhan penghasil nektar yang memadai yang terdapat di Pulau Puhawang Besar sehinga cukup mendukung bagi 
kelangsungan hidup kupu-kupu Nymphalidae. Semakin banyak ditemukannya spesies kupukupu disuatu tempat menandakan bahwa semakin beragamnya tumbuhan inang dan tumbuhan penghasil nektar di tempat tersebut (Soekardi, dkk., 2001).

Dengan terjadinya alih fungsi lahan yang digunakan sebagian besar sebagai daerah perkebunan dan pemukiman atau perumahan penduduk secara langsung dan tidak langsung akan mengancam keberadaan keanekaragaman hayati termasuk kupu-kupu. Daerah yang sudah mengalami alih fungsi lahan memiliki keanekaragaman spesies kupu-kupu yang lebih rendah daripada daerah yang dilindungi (Koh dan Sodhi, 2004). Menurut (Koneri, 2008) fragmentasi habitat karena alih fungsi lahan dapat mengurangi keanekaragaman spesies dan ukuran populasi. Kemungkinan pada proses pengolahan kebun menggunakan bahan-bahan kimia seperti herbisida dan pestisida. Selain itu, aktivitas berkebun ini meninggalkan sisa hasil berkebun seperti tumpukan kulit kelapa dan kulit cokelat yang sebagian besar dibakar di sekitar kebun. Kegiatan ini menimbulkan banyak asap serta dapat merusak habitat. Kondisi lingkungan seperti inilah yang dapat menyebabkan terjadinya perubahan lingkungan sehingga menyebabkan sedikitnya keanekaragaman kupukupu Nymphalidae. Kupu-kupu dapat dijadikan sebagai indikator kesehatan tanaman inang dan bagi ekosistem secara keseluruhan (Chowdhury and Soren, 2011).

\section{SIMPULAN}

Dari hasil penelitian yang telah dilakukan dapat disimpulkan bahwa:

1. Kupu-kupu Nymphalidae di Pulau Puhawang Besar yang ditemukan sebanyak 59 individu yang tergolong ke dalam 11 spesies.

2. Kupu-kupu yang memiliki kemelimpahan relatif tertinggi adalah Ypthima baldus, diikuti Danaus melanipus dan Orsotriaena medus sebesar sedangkan kupu-kupu yang memiliki kemelimpahan relatif terendah yaitu $\mathrm{Cu}$ pha erymanthis dan Euthalia monina $(1,69 \%)$.

3. Indeks keanekaragaman kupu-kupu Nymphalidae di Pulau Puhawang Besar termasuk dalam kategori sedang $(1,90)$.

\section{DAFTAR PUSTAKA}

Boonvanno, K., S. Watanasit and S. Permkamc. 2000. Butterfly Diversity at Ton Nga-Chang Wildlife Sanctuary, Songkhla Pro-vince, Southern Thailand. Science Asia 2 : 105-110.
Chowdhury, S. and R. Soren 2011. Butterfly (Le-pidoptera: Rhopalocera) Fauna of East Calcutta Wetlands, West Bengal, India. Check List Journal of Species Lists and Distribution 7(6) : 700-703.

Gillott, C. 2005. Entomology Third Edition. Springer. Dordrecth.

Handawa, Y. 2007. Pemetaan Kupu-kupu Nymphalidae di Kawasan Batutegi Tanggamus, Lampung (Skripsi). Jurusan Biologi FMIPA Universitas Lampung. Bandar Lampung.

Koh, K.P. dan N.S. Sodhi. 2004. Importance of Reverse, Fragments and Parks for Butterfly Conservation in A Tropical Urban Land-scape. Ecological Applications. 14 (6) : 1695-1708.

Koneri, R. 2008. Pengaruh Fragmentasi Habitat Terhadap Keragaman Serangga. FMIPA Universitas Sam Ratulangi. Manado. Pacific Journal 2(2) : 137-141.

Larasati, A. 2003. Keanekaragaman Kupukupu (Rhopalocera) Pada Dua Pulau Kecil di Teluk Lampung (Skripsi). Jurusan Biologi Institut Teknologi Bandung. Bandung.

Magguran, A.E. 1983. Ecological Diversity and It's Measurement. Chapman and Hall. London.

Mastrigt, H.V. dan E. Rosariyanto. 2005. Buku Panduan Kupu-kupu untuk Wilayah Membrano sampai Pegunungan Cyclops. Conservation International Indonesia. Jakarta.

Noprihatini, S. 2007. Keanekaragaman Kupukupu di Areal Penelitian Taman Nasional Bu-kit Barisan Selatan (Skripsi). Jurusan Biologi FMIPA Universitas Lampung. Bandar Lam-pung.

Novita. 2006. Pemetaan Kupu-kupu Nymphalidae di Taman Nasional Way Kambas Lampung (Skripsi). Jurusan Biologi FMIPA Universitas Lampung. Bandar Lampung.

Pegi, D. dan M. Amir. 2006. Panduan Praktis Kupu-kupu di Kebun Raya Bogor. Bidang Zoologi Pusat Penelitian LIPI Bogor. Cibinong.

Soekardi, H., A. Djausal dan S. Sastrodihardjo 2001. Taman Kupu-kupu Terbuka di Tanjung Manis Gunung Betung Lampung: Sebagai Suatu Model Konservasi Kupu-kupu. Prosiding Seminar Hasil Penelitian Dosen Unila. Lampung

Soekardi, H. 2007. Kupu-kupu di Kampus UNILA. Universitas Lampung Press. Bandar Lampung.

Sumarto, S dan P. Siahaan. 2012. Biogeografi. Alfabeta. Bandung.

Tsukada, E. dan Y. Nishiyama. 1982. Butterflies of the South East Asian Vol. 1 Papilionidae. Plapac Tokyo. Japan. Journal of Lepidopterist's Society. 44 (2) : 107-110.

Wibowo, D. 2009. Keanekaragaman Kupu-kupu Nymphalidae Berdasarkan Ketinggian Lokasi di Gunung Betung, Lampung (Skripsi). 
Jurusan Biologi FMIPA Universitas Lampung. Bandar Lampung.

Widhiono. 2004. Dampak Modifikasi Hutan Terhadap Keragaman Hayati Kupu-Kupu di Gunung Slamet Jawa Tengah. Biosfera 21(3) : 89-94. 